Review

\title{
Trichothecenes: From Simple to Complex Mycotoxins
}

\author{
Susan P. McCormick ${ }^{1}{ }^{*}$, April M. Stanley ${ }^{2}$, Nicholas A. Stover ${ }^{2}$ and Nancy J. Alexander ${ }^{1}$
}

1 Bacterial Foodborne Pathogens and Mycology, National Center for Agricultural Utilization

Research, U.S. Department of Agriculture-Agriculture Research Service, Peoria, IL 61604, USA;

E-Mail: Nancy.Alexander@ars.usda.gov

2 Biology Department, Bradley University, Peoria, IL 61625, USA;

E-Mails: misty717@sbcglobal.net (A.M.S.); nstover@bradley.edu (N.A.S.)

* Author to whom correspondence should be addressed; E-Mail: Susan.McCormick@ars.usda.gov; Tel.:+1-309-681-6381; Fax:+1-309-681-6627.

Received: 26 May 2011; in revised form: 10 June 2011 / Accepted: 29 June 2011 /

Published: 1 July 2011

\begin{abstract}
As the world's population grows, access to a safe food supply will continue to be a global priority. In recent years, the world has experienced an increase in mycotoxin contamination of grains due to climatic and agronomic changes that encourage fungal growth during cultivation. A number of the molds that are plant pathogens produce trichothecene mycotoxins, which are known to cause serious human and animal toxicoses. This review covers the types of trichothecenes, their complexity, and proposed biosynthetic pathways of trichothecenes.
\end{abstract}

Keywords: trichothecenes; mycotoxins; Type A; Type B; macrocyclic; d-type; t-type; toxin biosynthesis

\section{Introduction}

Fungi produce a large number of metabolites that are not essential for life, but may provide the fungus with an ecological advantage in certain environments. Such metabolites are referred to as secondary metabolites. Fungal secondary metabolites include plant growth regulators (e.g., gibberellins), pharmaceutically useful compounds (e.g., penicillin, lovastatin), pigments (e.g., carotenoids), and mycotoxins (e.g., trichothecenes, fumonisins, aflatoxins, ochratoxins) [1]. Mycotoxins may accumulate in infected crop plants, and upon ingestion, lead to the development of diseases (mycotoxicoses) in 
humans and animals [2]. Trichothecenes are one of the major classes of mycotoxins, causing a significant economic impact on cereal and grain crops each year [3,4]. An understanding of the pathogenicity of trichothecene-producing fungi and the regulation of trichothecene biosynthesis has become increasingly important to combat their spread throughout North America and other areas worldwide.

Trichothecene-producing genera include Fusarium, Myrothecium, Spicellum, Stachybotrys, Cephalosporium, Trichoderma, and Trichothecium [5]. These fungi, of the order Hypocreales, are found throughout the world and are adapted for colonization and growth on substrates with a wide range of moisture availability and nutrient content. Within the genus Fusarium, some species are important plant pathogens and are the causes of wilts, blights, and ear rots in grains, especially wheat, barley, oats and maize [4,6]. Myrothecium species are pathogens of muskmelon and tomato [7,8]. Stachybotrys is found in a variety of commodities and more recently, has been found to be a significant indoor environmental contaminant that has been correlated with damp building-related illnesses [9]. Trichoderma species are commonly found in the soil and have been associated with diseases of mushrooms and grapes [10]. Trichothecium species are commonly found in the soil and on decaying organic material [11].

Early toxicity studies showed that trichothecenes inhibit eukaryotic protein synthesis, specifically by preventing peptide bond formation at the peptidyl transferase center of the 60S ribosomal subunit. This inhibition typically affects polypeptide chain initiation or elongation, although polypeptide chain termination may also be inhibited [12-15]. Trichothecenes were later shown to inhibit mitochondrial protein synthesis [16,17] and to interact with protein sulfhydryl groups [18]. The activity of trichothecenes eventually produces harmful levels of oxidative stress due to generation of free radicals $[19,20]$.

Trichothecenes are small, amphipathic molecules that can move passively across cell membranes [21,22]. They are easily absorbed via the integumentary and gastrointestinal systems, allowing for a rapid effect of ingested trichothecenes on rapidly proliferating tissues [22]. Exposure to these toxins can cause feed refusal, immunological problems, vomiting, skin dermatitis, and hemorrhagic lesions [15,23]. They are also phytotoxic and can cause chlorosis, inhibition of root elongation, and dwarfism [14,24], and act as a virulence factor in wheat head scab [25-27].

Trichothecenes are a family of over 200 toxins with a common tricyclic 12,13-epoxytrichothec-9ene (EPT) core structure (Figure 1) [5,28]. They have been classified into four groups (Types A, B, C, and D) based on the substitution pattern of EPT (Figure 1) [29,30]. Types A, B and C can be differentiated based on the substitution at the C-8 position. Type A trichothecenes include compounds that have a hydroxyl group at C-8 (e.g., neosolaniol), an ester function at C-8 (e.g., T-2 toxin), or no oxygen substitution at C-8 (e.g., trichodermin, 4,15-diacetoxyscirpenol, and harzianum A). Type B trichothecenes have a keto (carbonyl) function at C-8 (e.g., nivalenol, deoxynivalenol, and trichothecin). In Fusarium, Type B trichothecenes typically have a C-7 hydroxyl group, but this structural feature is not present in other genera.

Type $\mathrm{C}$ trichothecenes have a C-7/C-8 epoxide (e.g., crotocin). Type D trichothecenes have an additional ring linking the $\mathrm{C}-4$ and $\mathrm{C}-15$ position (e.g., roridin $\mathrm{A}$, verrucarin $\mathrm{A}$, satratoxin $\mathrm{H}$ ). Although this classification system has continued to be used [31-33], there are other structural features that are not accounted for with this system. For example, all Fusarium trichothecenes (including 
Type A and Type B) have an oxygen function (i.e., a hydroxyl or an acetyl group) at C-3. Trichothecenes produced by Trichoderma, Trichothecium, Myrothecium or Stachybotrys (including Types $\mathrm{A}, \mathrm{B}, \mathrm{C}$ and D) lack an oxygen function at the C-3 position. With the current ability to study the genetic control of trichothecene biosynthesis, a genetic approach to trichothecene classification is possible.

Figure 1. Classification of trichothecene structures. EPT (12,13-epoxytrichothec-9-ene); $\mathrm{R}$ groups may be $\mathrm{H}, \mathrm{OH}$, OAcyl, or variations in the macrolide chain.
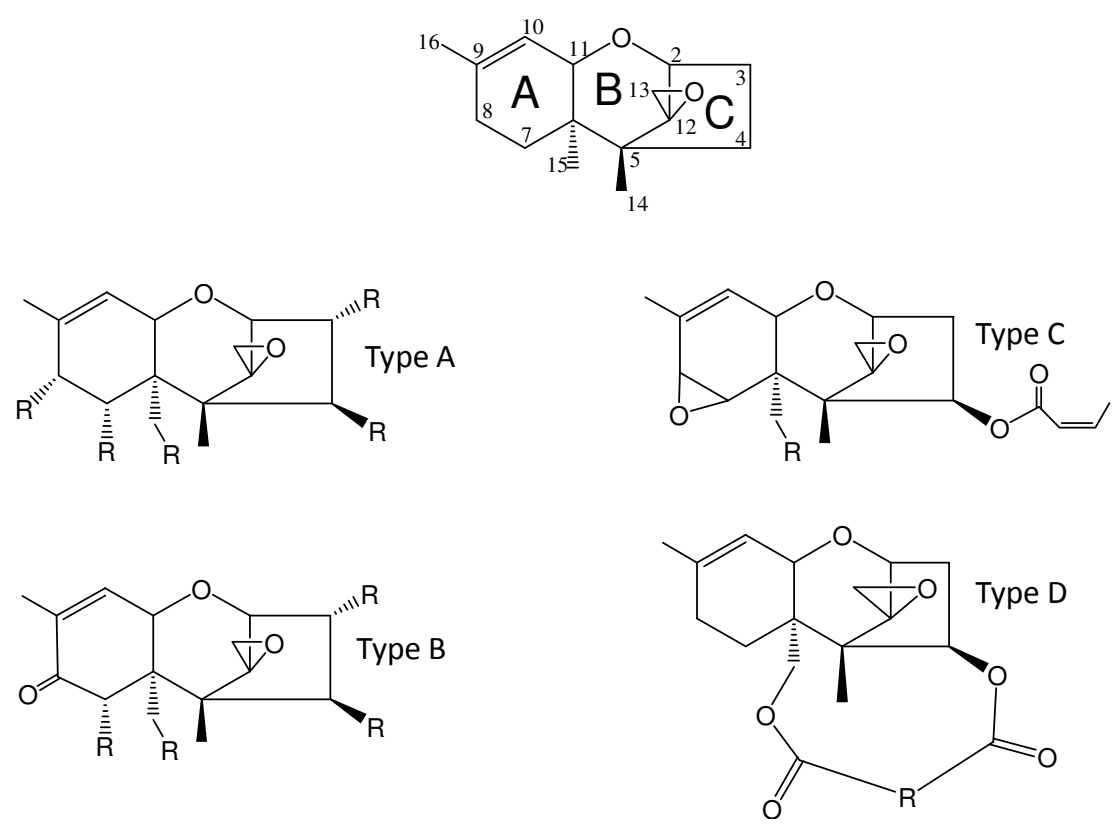

\section{Trichothecene Biosynthesis in Fusarium}

Biosynthesis of Fusarium trichothecenes begins with the cyclization of farnesyl pyrophosphate, a primary metabolic intermediate, to form trichodiene. The terpene cyclase trichodiene synthase (Tri5) that catalyzes this reaction and the gene that encodes it (TRI5) were first characterized in a T-2 toxin (Type A trichothecene) producing strain of Fusarium sporotrichioides [34,35] (for the Fusarium trichothecene biosynthetic pathways, see Figure 2). Trichodiene undergoes a series of oxygenations catalyzed by a cytochrome P450 monooxygenase encoded by TRI4 [36]. In Fusarium species, TRI4 controls the addition of four oxygens at $\mathrm{C}-2, \mathrm{C}-3, \mathrm{C}-11$, and the $\mathrm{C}-12, \mathrm{C}-13$-epoxide to form the intermediate isotrichotriol [37].

Isotrichotriol undergoes a non-enzymatic isomerization and cyclization to form isotrichodermol (=3a-hydroxy EPT) [38]. During this process, the oxygen at the C-2 position becomes the pyran ring oxygen and the hydroxyl group at $\mathrm{C}-11$ is lost. More complex Type A trichothecenes are built by modifying isotrichodermol through a series of paired hydroxylation $(-\mathrm{OH})$ and acetylation or acylation (-OR) steps (Figure 3).

Isotrichodermol $(\mathrm{C}-3-\mathrm{OH})$ is converted to isotrichodermin $(\mathrm{C}-3-\mathrm{OR})$ (Figure 2) by an acetyltransferase encoded by TRIIO1 [39]. This step effectively reduces the toxicity of Fusarium trichothecenes, thereby serving as a mechanism for the self-protection of the trichothecene-producing organism [40]. A second hydroxyl group is added to C-15 (controlled by TRI11) [41], which is subsequently acetylated under the control of TRI3 [42,43]. A third hydroxyl group is added at C-4 
(controlled by TRI13) [44,45], which is subsequently acetylated under the control of TRI7 [44]. In F. sporotrichioides, a Type A producer, a fourth hydroxyl group is added to C-8 (controlled by TRI1), followed by the addition of an isovaleryl moiety controlled by TRII6. Finally, the acetyl group is removed from the $\mathrm{C}-3$ position by an esterase (controlled by TRI8) to produce T-2 toxin [46].

Biosynthesis of Fusarium Type B trichothecenes, e.g., 15-ADON or 4,15-diANIV, follows a pathway similar to that of Type A trichothecenes, with paired hydroxylations and acetylations at C-3 and C-15, or at C-3, C-15 and C-4 (Figure 2 and 3). However, rather than TRII controlling the final hydroxylation at C-8 as in Type A-producing strains, TRII in Type B-producing strains controls the addition of hydroxyl groups at both the C-7 and C-8 positions [47,48]. The C-8 hydroxyl group is then converted to a keto function for which the genetic control has not been fully characterized. In Fusarium, presence of a C-7 hydroxyl group is correlated with the conversion of the C-8 hydroxyl group to a keto function. The final step in Fusarium Type B trichothecene biosynthesis is the removal of the C-3 acetyl group, or the C-15 acetyl group, by an esterase encoded by TRI8. Differential activity of this esterase, as defined by the DNA sequence, determines production of either 3-ADON or 15-ADON chemotypes in $F$. graminearum [49].

Figure 2. Proposed trichothecene biosynthetic pathway in Fusarium. Genes encoding an enzymatic step are identified near the arrow indicating the step. Dashed arrows indicate steps for which a gene has not been assigned. Green box indentifies Type B trichothecenes.

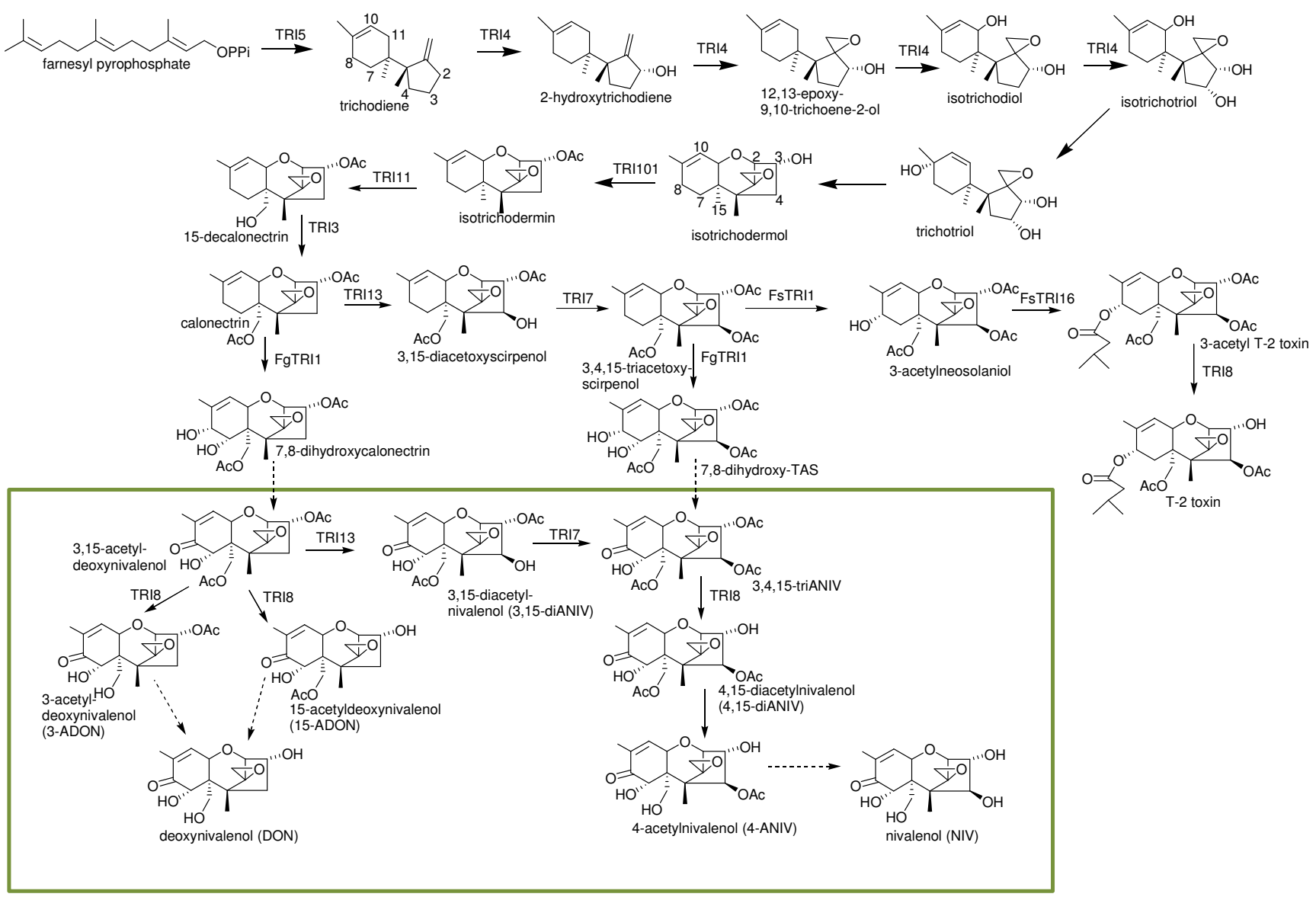


Figure 3. Proposed trichothecene biosynthetic pathways illustrating the divergence into the d-type (from isotrichodiol) (orange box) and the t-type (from isotrichotriol) (violet box) trichothecenes. Blue boxes indicate Type A trichothecenes; green boxes indicate Type B trichothecenes; red box indicates Type D trichothecene.

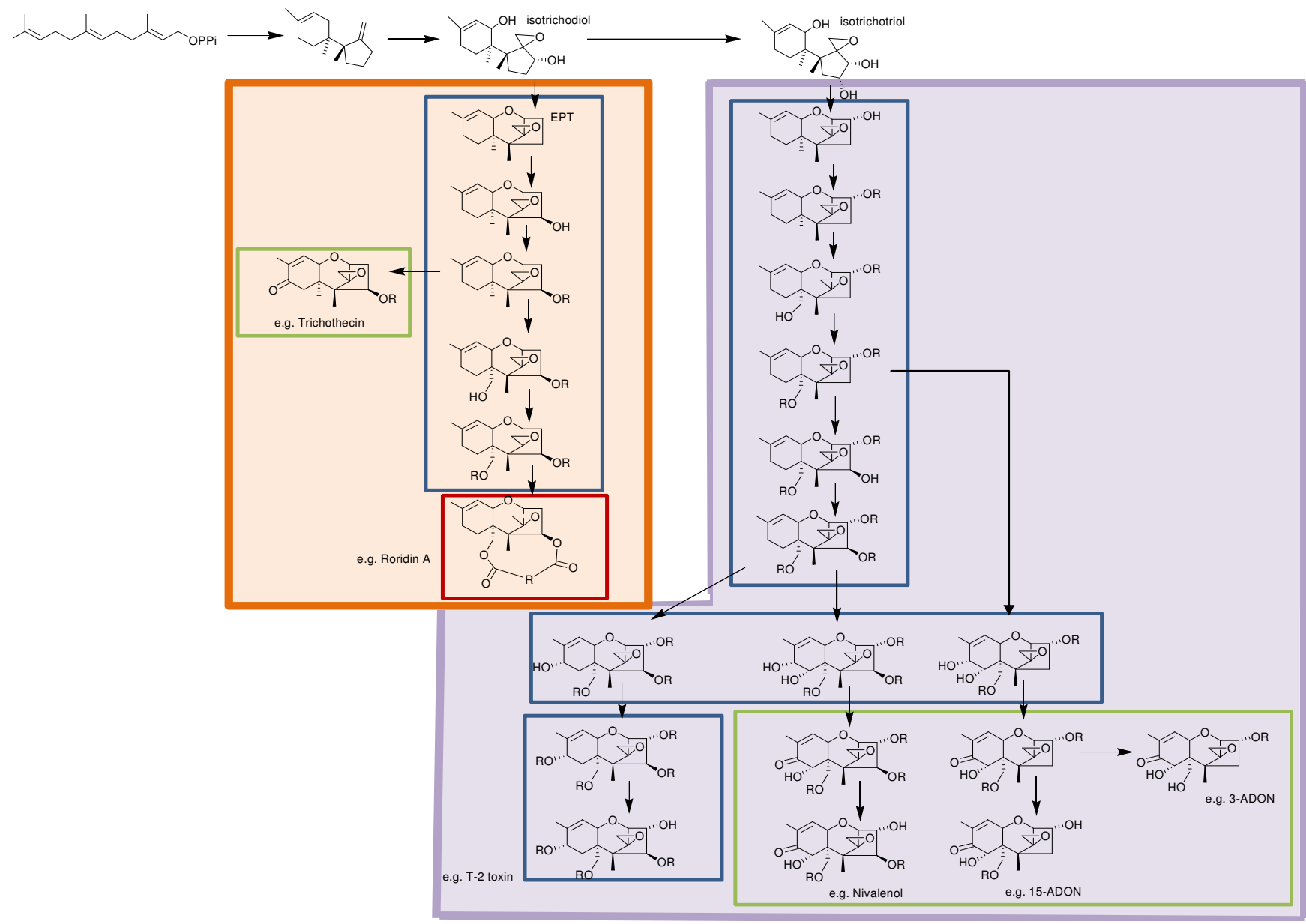

\section{Trichothecene Biosynthesis in Other Genera}

Biosynthesis of trichothecenes in other genera also begins with the cyclization of farnesyl pyrophosphate to form trichodiene (Figure 3). Homologs of Fusarium TRI5 that control this step have been identified in Myrothecium roridum [50], Trichothecium roseum [51], Trichoderma harzianum [52], and T. brevicompactum [53].

Most trichothecenes produced by Myrothecium, Trichothecium, Trichoderma and other genera lack a C-3 hydroxyl group. Homologs of Fusarium TRI4 have been identified in Myrothecium roridum [50] and Trichothecium roseum [51] and in these genera, TRI4 controls the addition of only three, rather than four, oxygens: hydroxyl groups at $\mathrm{C}-2$ and $\mathrm{C}-11$, and the $\mathrm{C}-12, \mathrm{C}-13$ epoxide, converting trichodiene into isotrichodiol [51,54]. However, T. roseum produces two types of trichothecenes, those that lack a C-3 oxygen function (e.g., trichothecin), and those that have a C-3 hydroxyl group (e.g., trichothecinol A) [5,55]. It is not known if the C-3 hydroxyl group is added prior to cyclization or exactly which gene controls this oxygenation step.

Non-enzymatic isomerization and cyclization of isotrichodiol, with loss of a hydroxyl group, forms 12,13-epoxytrichothec-9-ene (EPT). More complex trichothecenes are formed from EPT by a series of 
hydroxylation $(-\mathrm{OH})$ and esterification (-OR) reactions (Figure 3). Although the genes and enzymes for these steps have not been characterized, the types of genes required can be discerned from the structures of the toxins. The relatively simple Type A trichothecene, trichodermin, produced by Trichoderma brevicompactum, requires only the addition of a single hydroxyl group at C-4 by a P450 oxygenase $(-\mathrm{OH})$, followed by an acetylation at that position (-OR). Biosynthesis of harzianum A, a Type A trichothecene produced by $T$. arundinacium, requires C-4 hydroxylation and esterification with a polyketide side chain. This type of substitution necessitates the involvement of a polyketide synthase as well as a transferase. Biosynthesis of trichothecin, a Type B trichothecene produced by Trichothecium roseum, is likely formed from EPT also. In this case, EPT undergoes hydroxylation at $\mathrm{C}-4(-\mathrm{OH})$ followed by esterification with a butyryl group (-OR), which is then followed by a second hydroxylation at C-8 $(-\mathrm{OH})$. Conversion of the C-8 hydroxyl group to a keto produces trichothecin, a type B trichothecene group. Although Fusarium Type B trichothecenes typically have an 8-oxo, C-7 hydroxyl substitution pattern, Type B trichothecenes in other genera lack a C-7 hydroxyl group.

Macrocyclic trichothecenes lack a C-3 oxygen function, indicating that their biosynthesis proceeds from isotrichodiol and EPT. To build these compounds, the initial hydroxylation and esterification of a polyketide at $\mathrm{C}-4$ is followed by the addition of a hydroxyl group (e.g., trichoverrol A) and then a polyketide ester at C-15 (e.g., trichoverrin A). Condensation of the C-4 and C-15 polyketide chains would result in a Type D macrocyclic trichothecene [10].

\section{Genetic Approach to Trichothecene Classification}

In fungi, genes responsible for the biosynthesis of secondary metabolites are typically located next to one another in gene clusters [1,50,56,57]. In Fusarium, trichothecene genes (TRI) are found at three loci [58,59]: a 26-kb core TRI cluster containing most of the genes that control trichothecene biosynthesis [60]; a two-gene TRI1-TRII6 cluster [61,62]; and the TRI101 locus [63]. In addition, TRI15, which appears to negatively control trichothecene biosynthesis, is located outside the core cluster [64] and may be part of a siderophore biosynthesis gene cluster [65]. In some species (e.g., F. equiseti), TRII and TRI101 are inserted into the core cluster suggesting a complex evolutionary history of the trichothecene genes [59]. The functions of most of these genes in the biosynthesis, regulation of biosynthesis and transport of trichothecenes, have been characterized in Fusarium and reviewed $[58,66]$. The identification of genes and their proteins now enable us to view how genetic changes lead to different types of trichothecenes.

Table 1 shows the chemical classification of nineteen representative trichothecenes by four different methods. Although the Type A, B, C, and D classification is commonly used, other classifications have been suggested. Trichothecenes can be classified as simple or macrocyclic. Biosynthesis of both simple trichothecenes (Type A, B, or C) and macrocyclic trichothecenes (Type D) is actually via Type A trichothecene intermediates (Figure 3). Grove [67] focused on conformational differences and reactivity of functional groups, and designated three groups of simple trichothecenes. Group I contains trichothecenes that have substitutions only on ring $\mathrm{C}$ (see Figure 1 for ring identification), e.g., trichodermin, isotrichodermin; Group II contains trichothecenes which have additional substituents in ring A, e.g., T-2 toxin and 7,8-dihydroxycalonectrin (Figures 1 and 2); and Group III 
contains trichothecenes that have a keto at C-8, e.g., DON or trichothecin, the same criteria for Type B trichothecenes.

Kimura et al. [68] proposed dividing trichothecenes into two groups based on whether they are derived from isotrichodiol (d-type) or isotrichotriol (t-type) (Figure 3). This classification turns out to be genetically based on functional differences in TRI4, which controls the addition of either 4 oxygens, as in Fusarium sp. (t-type), or 3 oxygens as in other genera (d-type) [37,51,54] (Figure 3). Phylogenetic analyses may help to determine how d-type and t-type trichothecenes evolved.

Table 1. Classification of selected trichothecenes.

\begin{tabular}{|c|c|c|c|c|}
\hline Trichothecene & $\begin{array}{c}\text { Simple or Macrocyclic } \\
\text { (S or M) }\end{array}$ & Type $^{1}$ & Group $^{2}$ & Type $^{3}$ \\
\hline 1 trichodermol & $\mathrm{S}$ & $\mathrm{A}$ & $\mathrm{I}$ & $\mathrm{d}$ \\
\hline 2 trichodermin & $S$ & $\mathrm{~A}$ & $\mathrm{I}$ & $\mathrm{d}$ \\
\hline 3 4,15-Diacetoxyscirpenol (DAS) & $\mathrm{S}$ & $\mathrm{A}$ & & $\mathrm{t}$ \\
\hline 4 neosolaniol & $S$ & $\mathrm{~A}$ & II & $\mathrm{t}$ \\
\hline $5 \mathrm{~T}-2$ toxin & $S$ & $\mathrm{~A}$ & II & $\mathrm{t}$ \\
\hline 6 isotrichodermol & $S$ & $\mathrm{~A}$ & $\mathrm{I}$ & $\mathrm{t}$ \\
\hline 7 calonectrin & $\mathrm{S}$ & $\mathrm{A}$ & & $\mathrm{t}$ \\
\hline 8 7,8-dihydroxy calonectrin & $\mathrm{S}$ & $\mathrm{A}$ & II & $\mathrm{t}$ \\
\hline 9 harzianum $\mathrm{A}$ & $S$ & A & & $\mathrm{d}$ \\
\hline 10 nivalenol (NIV) & $S$ & $\mathrm{~B}$ & III & $\mathrm{t}$ \\
\hline 11 deoxynivalenol (DON) & $\mathrm{S}$ & $\mathrm{B}$ & III & $\mathrm{t}$ \\
\hline 12 fusarenon- $X$ & $\mathrm{~S}$ & $\mathrm{~B}$ & III & $\mathrm{t}$ \\
\hline 13 trichothecin & $\mathrm{S}$ & $\mathrm{B}$ & III & $\mathrm{d}$ \\
\hline 14 trichothecinol A & $\mathrm{S}$ & $\mathrm{B}$ & III & $\mathrm{t}$ \\
\hline 15 crotocin & $\mathrm{S}$ & $\mathrm{C}$ & & $\mathrm{d}$ \\
\hline 16 satratoxin $\mathrm{H}$ & $\mathrm{M}$ & $\mathrm{D}$ & & $\mathrm{d}$ \\
\hline 17 roridin $\mathrm{A}$ & $\mathrm{M}$ & $\mathrm{D}$ & & $\mathrm{d}$ \\
\hline 18 baccharin & $\mathrm{M}$ & $\mathrm{D}$ & & $\mathrm{d}$ \\
\hline 19 verrucarin $A$ & $\mathrm{M}$ & $\mathrm{D}$ & & $\mathrm{d}$ \\
\hline
\end{tabular}

${ }^{1}$ Based on presence of C-8 keto group (Type B), C-7, C-8 epoxy (Type C), ring connecting C-4 and C-15 (Type D) [29]; ${ }^{2}$ Based on substitutions in the $\mathrm{A}$ and $\mathrm{C}$ ring [67]; ${ }^{3}$ Based on presence (t-type)or absence (d-type) of C-3 oxygen function [40].

Relating toxicity of individual trichothecenes based on any of these classification systems is not always straightforward. Macrocyclic trichothecenes (e.g., roridins, verrucarins and satratoxins) are considered to be some of the most toxic trichothecenes and are generally more toxic than simple trichothecenes $[9,69]$. Type A trichothecenes such as DAS and T-2 toxin are generally more cytotoxic than Type B trichothecenes such as DON [29]. Animal toxicity increases with increasing oxygenation of EPT [70]. Testing of Fusarium trichothecenes on the model plant system Chlamydomonas showed that both Type A and Type B C-3 acetylated trichothecenes are much less toxic than the corresponding C-3 hydroxyl trichothecenes [71]. In Fusarium, one gene, TRI101, controls this change in toxicity. A more extensive survey of trichothecenes for phytotoxicity showed that there can be wide variation in the phytotoxicity within Type A trichothecenes and that some are relatively non-toxic [72]. In addition, 
this study found that small structural changes can result in large changes in toxicity and that some Type B trichothecenes are relatively more toxic than Type A trichothecenes. Therefore, the degree of toxicity of trichothecenes does not necessarily correlate with chemical classification.

\section{Conclusions}

In recent years, the world has experienced an increase in awareness of mycotoxin contamination of grains, building materials, and air-handling systems. Many of these problems are caused by trichothecenes, which range from those with relatively simple structures to those with more complex, macrocyclic structures. Gene identification has begun to clarify how trichothecenes are made. As more genetic sequence data becomes available, phylogenetic analyses may lead to a better understanding of the evolution of trichothecene-producing fungi. Phylogenetic work on the trichothecene gene cluster indicates that, through time, there has been consolidation of TRI genes into fewer loci in some fusaria while three distinct TRI loci have been maintained in other fusaria [59]. Continued studies will help to clarify how evolution affects mycotoxin-producing genes. Using gene sequences from one organism also helps in the identification of trichothecene genes and pathways in other organisms, such as using Fusarium genes to identify those in Trichoderma (Santiago Gutiérrez, personal communication). Studying fungal populations and genetic linkages will also bring a better understanding of how pathogenic fungi spread throughout the world [73-76]. Comparison of gene sequences from expanding databases may also contribute to identification of trichothecene-related genes that may lead to new control strategies to reduce both crop diseases caused by the fungi and the mycotoxin contamination problems associated with these diseases. The combination of chemical and genetic analysis of trichothecene biosynthesis may lead to a better understanding of the evolution and phylogenetics of the trichothecenes.

\section{Acknowledgments}

In fond memory of Samuel Fan, former member of the Bradley University Biology Department, for guidance and support during this project.

\section{References}

1. Keller, N.P.; Turner, G.; Bennett, J.W. Fungal secondary metabolism-from biochemistry to genomics. Nat. Rev. Microbiol. 2005, 3, 937-947.

2. Ueno, Y. Mode of action of trichothecenes. Pure Appl. Chem. 1977, 49, 1737-1745.

3. Parry, D.W.; Jenkinson, P.; McLeod, L. Fusarium ear blight (scab) in small grain cereals-a review. Plant Pathol. 1995, 44, 207-238.

4. McMullen, M.; Jones, R.; Gallenberg, D. Scab of wheat and barley: A re-emerging disease of devastating impact. Plant Dis. 1997, 81, 1340-1348.

5. Cole, R.A.; Jarvis, B.B.; Schweikert, M.A. Handbook of Secondary Metabolites; Academic Press: New York, NY, USA, 2003; pp. 199-560.

6. Desjardins, A.E. Fusarium Mycotoxins Chemistry, Genetics and Biology; APS Press: Eagan, MN, USA, 2006; pp. 1-260. 
7. Bean, G.A.; Fernando, T.; Jarvis, B.B.; Burton, B. The isolation and identification of trichothecene metabolites from a plant pathogenic strain of Myrothecium roridum. J. Nat. Prod. 1984, 47, 727-729.

8. Kuti, J.O.; Ng, T.J.; Bean, G.A. Possible involvement of a pathogen-produced trichothecene metabolite in Myrothecium leaf spot of muskmelon. Physiol. Mol. Plant Pathol.1989, 34, 41-54.

9. Pestka, J.J.; Forstell, J.H. Inhibition of human lymphocyte transformation by the macrocyclic trichothecenes roridin A and verrucarin A. Toxicol. Lett. 1988, 41, 215-222.

10. Degenkolb, T.; Dieckmann, R.; Nielsen, K.F.; Gräfenhan, T.; Theis, C.; Zafari, D.; Chaverri, P.; Ismaiel, A.; Brückner, H.; von Döhren, H.; et al. The Trichoderma brevicompactum clade: A separate lineage with new species, new peptaibiotics, and mycotoxins. Mycol. Prog. 2008, 7 , 177-219.

11. Farr, D.F.; Bills, G.F.; Chamuris, G.P.; Rossman, A.Y. Fungi on Plants and Plant Products in the United States; APS Press: Eagan, MN, USA, 1989.

12. Carrasco, L.; Barbacid, M.; Vazquez, D. The trichodermin group of antibiotics, inhibitors of peptide bond formation by eukaryotic ribosomes. Biochim. Biophys. Acta 1973, 312, 368-376.

13. Cundliffe, E.; Cannon, M.; Davies, J. Mechanism of inhibition of eukaryotic protein synthesis by trichothecene fungal toxins. Proc. Natl. Acad. Sci. USA 1974, 71, 30-34.

14. Cundliffe, E.; Davies, J.E. Inhibition of initiation, elongation, and termination of eukaryotic protein synthesis by trichothecene fungal toxins. Antimicrob. Agents Chemother. 1977, 11, 491-499.

15. Ueno, Y. The toxicology of mycotoxins. Crit. Rev. Toxicol. 1985, 14, 99-132.

16. Pace, J.G.; Watts, M.R.; Canterbury, W.J. T-2 mycotoxin inhibits mitochondrial protein synthesis. Toxicon 1988, 26, 77-85.

17. McLaughlin, J.E.; Bin-Umer, M.A.; Tortora, A.; Mendeze, N.; McCormick, S.; Tumer, N.E. A genome-wide screen in Saccharomyces cerevisiae reveals a critical role for the mitochondria in the toxicity of a trichothecene mycotoxin. Proc. Natl. Acad. Sci. USA 2009, 106, 21883-21888.

18. Ueno, Y.; Matsumoto, H. Inactivation of some thiol-enzymes by trichothecene mycotoxins from Fusarium species. Chem. Pharm. Bull. 1975, 23, 2439-2442.

19. Suneja, S.K.; Wagle, D.S.; Ram, G.C. Effect of oral administration of T-2 toxin on glutathione shuttle enzymes, microsomal reductases and lipid peroxidation in rat liver. Toxicon 1989, 27, 995-1001.

20. Riley, R.T.; Norred, W.P. Mechanisms of Mycotoxicity. In The Mycota VI: Human and Animal Relationships; Howard, D.H., Miller, J.D., Eds.; Springer-Verlag: New York, NY, USA, 1996; pp. 193-211.

21. Middlebrook, J.L.; Leatherman, D.L. Specific associations of T-2 toxin with mammalian cells. Biochem. Pharmacol. 1989, 38, 3093-3102.

22. Wannemacher, R.W.; Winer, S.L. Trichothecene Mycotoxins. In Medical Aspects of Chemical and Biological Warfare; Sidell, R.R., Takafuji, E.T., Franz, D.R., Eds.; Office of the Surgeon General at TMM Publications: Washington, DC, USA, 1977; pp. 655-676.

23. Pestka, J.J. Mechanisms of deoxynivalenol-induced gene expression and apoptosis. Food Addit. Contam. 2008, 22, 1128-1140. 
24. McLean, M. The phytotoxicity of Fusarium metabolites: An update since 1989. Mycopathologia 1996, 133, 163-179.

25. Proctor, R.H.; Hohn, T.M.; McCormick, S.P. Reduced virulence of Gibberella zeae caused by disruption of a trichothecene toxin biosynthetic gene. Mol. Plant-Microbe Interact. 1995, 61, 1923-1930.

26. Proctor, R.H.; Hohn, T.M.; McCormick, S.P. Restoration of wild-type virulence to Tri5 disruption mutants of Gibberella zeae via gene reversion and mutant complementation. Microbiology 1997, 143, 2583-2591.

27. Desjardins, A.E.; Proctor, R.H.; Bai, G.; McCormick, S.P.; Shaner, G.; Beuchley, G.; Hohn, T.M. Reduced virulence of trichothecene-non-producing mutants of Gibberella zeae in wheat field tests. Mol. Plant-Microbe Interact. 1996, 9, 1996-1023.

28. Grove, J.F. The trichothecenes and their biosynthesis. Prog. Chem. Org. Nat. Prod. 2007, 88, 63-130.

29. Ueno, Y. Toxicological features of T-2 toxin and related trichothecenes. Fundam. Appl. Toxicol. 1984, 4, S124-S132.

30. Ueno, Y. Mode of action of trichothecenes. Ann. Nutr. Aliment. 1977, 31, 885-900.

31. Altomare, C.; Logrieco, A.; Bottalico, A.; Mulé, G.; Moretti, A.; Evidente, A. Production of type $\mathrm{S}$ trichothecenes and enniatin B by Fusarium sambucinum Fuckel sensu lato. Mycopathologia 1995, 129, 177-181.

32. Gottschalk, C.; Barthel, J.; Engelhardt, G.; Bauer, J.; Meyer, K. Simultaneous determination of type A, B and D trichothecenes and their occurrence in cereals and cereal products. Food Addit. Contam. A 2009, 26, 1273-1289.

33. Garvey, G.S.; McCormick, S.P.; Rayment, I. Structural and functional characterization of the TRI101 trichothecene 3-0-acetyltransferase from Fusarium sporotrichioides and Fusarium graminearum: Kinetic insights to combating Fusarium head blight. J. Biol. Chem. 2008, 283, 1660-1669.

34. Hohn, T.M.; VanMiddlesworth, F. Purification and characterization of the sesquiterpene cyclase trichodiene synthetase from Fusarium sporotrichioides. Arch. Biochem. Biophys. 1986, 251, 756-761.

35. Hohn, T.M.; Beremand, P.D. Isolation and nucleotide sequence of a sesquiterpene cyclase gene from the trichothecene-producing fungus Fusarium sporotrichioides. Gene 1989, 79, 131-138.

36. Hohn, T.M.; Desjardins, A.E.; McCormick, S.P. The Tri4 gene of Fusarium sporotrichioides encodes a cytochrome P450 monooxygenase involved in trichothecene biosynthesis. Mol. Plant-Microbe Interact. 1995, 248, 95-102.

37. McCormick, S.P.; Alexander, N.J.; Proctor, R.H. Fusarium Tri4 encodes a multifunctional oxygenase required for trichothecene biosynthesis. Can. J. Microbiol. 2006, 52, 636-642.

38. McCormick, S.P.; Taylor, S.L.; Plattner, R.D.; Beremand, M.N. Bioconversion of possible T-2 toxin precursors by a mutant strain of Fusarium sporotrichioides. Appl. Environ. Microbiol. 1990, 56, 702-706.

39. McCormick, S.P.; Alexander, N.J.; Trapp, S.E.; Hohn, T.M. Disruption of TRI101, the gene encoding trichothecene 3-O-acetyltransferase, from Fusarium sporotrichioides. Appl. Environ. Microbiol. 1999, 65, 5252-5256. 
40. Kimura, M.; Kaneko, I.; Komiyama, M.; Takatsuki, A.; Koshino, H.; Yoneyama, K.; Yamaguchi, I. Trichothecene 3-O-acetyltransferase protects both the producing organism and transformed yeast from related mycotoxins. J. Biol. Chem. 1998, 273, 1654-1661.

41. Alexander, N.J.; Hohn, T.M.; McCormick, S.P. The TRII1 gene of Fusarium sporotrichioides encodes a cytochrome $\mathrm{P} 450$ monooxygenase required for $\mathrm{C}-15$ hydroxylation in trichothecene biosynthesis. Appl. Environ. Microbiol. 1998, 64, 221-225.

42. McCormick, S.P.; Hohn, T.M.; Desjardins, A.E. Isolation and characterization of Tri3, a gene encoding 15-O-acetyltransferase from Fusarium sporotrichioides. Appl. Environ. Microbiol. 1996, 62, 353-359.

43. Garvey, G.S.; McCormick, S.P.; Alexander, N.J.; Rayment, I. Structural and functional characterization of TRI3 trichothecene 15-O-acetyltransferase from Fusarium sporotrichioides. Protein Sci. 2009, 18, 747-761.

44. Lee, T.; Han, Y.-K.; Kim, K.-H.; Yun, S.-H.; Lee, Y.-W. Tril3 and Tri7 determine deoxynivalenol- and nivalenol-producing chemotypes of Gibberella zeae. Appl. Environ. Microbiol. 2002, 68, 2148-2154.

45. Brown, D.W.; McCormick, S.P.; Alexander, N.J.; Proctor, R.H.; Desjardins, A.E. Inactivation of a cytochrome P-450 is a determinant of trichothecene diversity in Fusarium species. Fungal Genet. Biol. 2002, 36, 224-233.

46. McCormick, S.P.; Alexander, N.J. Fusarium Tri8 encodes a trichothecene C-3 esterase. Appl. Environ. Microbiol. 2002, 68, 2959-2964.

47. McCormick, S.P.; Harris, L.J.; Alexander, N.J.; Ouellet, T.; Saparno, A.; Allard, S.; Desjardins, A.E. Tril in Fusarium graminearum encodes a P450 oxygenase. Appl. Environ. Microbiol. 2004, 70, 2044-2051.

48. McCormick, S.P.; Alexander, N.J.; Proctor, R.H. Heterologous expression of two trichothecene P450 genes in Fusarium verticillioides. Can. J. Microbiol. 2006, 52, 220-226.

49. Alexander, N.J.; McCormick, S.P.; Waalwijk, C.; van der Lee, T.; Proctor, R.H. The genetic basis for 3-ADON and 15-ADON trichothecene chemotypes in Fusarium graminearum. Fungal Genet. Biol. 2011, 48, 485-495.

50. Trapp, S.E.; Hohn, T.M.; McCormick, S.P.; Jarvis, B.B. Characterization of the gene cluster for biosynthesis of macrocyclic trichothecenes in Myrothecium roridum. Mol. Gen. Genet. 1998, 257, 421-432.

51. Tokai, T.; Koshino, H.; Takahashi-Ando, N.; Sato, M.; Fujimura, M.; Kimura, M. Fusarium Tri4 encodes a key multifunctional cytochrome P450 monooxygenase for four consecutive oxygenation steps in trichothecene biosynthesis. Biochim. Biophys. Acta 2007, 353, 412-417.

52. Gallo, A.; Mulé, G.; Favilla, M.; Altomare, C. Isolation and characterisation of a trichodiene synthase homologous gene in Trichoderma harzianum. Physiol. Mol. Plant Pathol. 2004, 65, 11-20.

53. Tijerino, A.; Cardoza, R.E.; Moraga, J.; Malmierca, M.G.; Vicente, F.; Aleu, J.; Collado, I.G.; Gutiérrez, S.; Monte, E.; Hermosa, R. Overexpression of trichodiene synthase gene tri5 increases trichodermin production and antimicrobial activity in Trichoderma brevicompactum. Fungal Genet. Biol. 2011, 48, 285-296. 
54. McCormick, S.P.; Alexander, N.J. Myrothecium roridum Tri4 encodes a multifunctional oxygenase required for three oxygenation steps. Can. J. Microbiol. 2007, 53, 572-579.

55. Iida, A.; Knoisha, K.; Kubo, H.; Tomioka, K.; Tokuda, H.; Nishino, H. Trichothecinols A, B and C. Potent anti-tumor promoting sesquiterpenoids from the fungus Trichothecium roseum. Tetrahedron Lett. 1996, 51, 9219-9220.

56. Hohn, T.M.; McCormick, S.P.; Desjardins, A.E. Evidence for a gene cluster involving trichothecene-pathway biosynthetic genes in Fusarium sporotrichioides. Curr. Genet. 1993, 24, 291-295.

57. Keller, N.P.; Hohn, T.M. Metabolic pathway gene clusters in filamentous fungi. Fungal Genet. Biol. 1997, 21, 17-29.

58. Alexander, N.J.; Proctor, R.H.; McCormick, S.P. Genes, gene clusters, and biosynthesis of trichothecenes and fumonisins in Fusarium. Toxin Rev. 2009, 28, 198-215.

59. Proctor, R.H.; McCormick, S.P.; Alexander, N.J.; Desjardins, A.E. Evidence that a secondary metabolic biosynthetic gene cluster has grown by gene relocation during evolution of the filamentous fungus Fusarium. Mol. Microbiol. 2009, 74, 1128-1142.

60. Brown, D.W.; Dyer, R.B.; McCormick, S.P.; Kendra, D.F.; Plattner, R.D. Functional demarcation of the Fusarium core trichothecene gene cluster. Fungal Genet. Biol. 2004, 41, 454-462.

61. Meek, I.B.; Peplow, A.W.; Ake, C., Jr.; Phillips, T.D.; Beremand, M.N. Tril encodes the cytochrome $\mathrm{P} 450$ monooxygenase for $\mathrm{C}-8$ hydroxylation during trichothecene biosynthesis in Fusarium sporotrichioides. Appl. Environ. Microbiol. 2003, 69, 1607-1613.

62. Peplow, A.W.; Meek, I.B.; Wiles, M.C.; Phillips, T.D.; Beremand, M.N. Tri16 is required for esterification of position C-8 during trichothecene mycotoxin production by Fusarium sporotrichioides. Appl. Environ. Microbiol. 2003, 69, 5935-5940.

63. Kimura, M.; McAlees, A.J.; Shingu, Y.; Yoneyama, K.; Yamaguchi, I. The mystery of the trichothecene 3-O-acetyltransferase gene. FEBS Lett. 1998, 435, 163-168.

64. Alexander, N.J.; McCormick, S.P.; Larson, T.M.; Jurgenson, J.E. Expression of Tri15 in Fusarium sporotrichioides. Curr. Genet. 2004, 45, 157-162.

65. Seong, K.-Y.; Pasquali, M.; Zhou, X.; Song, J.; Hilbrun, K.; McCormick, S.P.; Dong, Y.; Xu, J.R.; Kistler, H.C. Global gene regulation by Fusarium transcription factors Tri6 and Tri10 reveals adaptations for toxin biosynthesis. Mol. Microbiol. 2009, 72, 354-367.

66. Kimura, M.; Tokai, T.; Takahashi-Ando, N.; Ohsato, S.; Fujimura, M. Molecular and genetic studies of Fusarium trichothecene biosynthesis: Pathways, genes and evolution. Biosci. Biotechnol. Biochem. 2007, 2105-2123.

67. Grove, J.F. Non-macrocyclic trichothecenes. Nat. Prod. Rep. 1988, 5, 187-209.

68. Kimura, M.; Shingu, Y.; Yoneyama, K.; Yamaguchi, I. Features of Tri101, the trichothecene 3-O-acetyltransferase gene, related to the self-defense mechanism in Fusarium graminearum. Biosci. Biotechnol. Biochem. 1998, 62, 1033-1036.

69. Islam, Z.; Shinozuka, J.; Harkema, J.R.; Pestka, J.J. Purification and comparative neurotoxicity of the trichothecenes satratoxin G and roridin L2 from Stachybotrys chartarum. J. Toxicol. Environ. Health A 2009, 72, 1242-1251. 
70. Bondy, G.S.; McCormick, S.P.; Beremand, M.N.; Pestka, J.J. Murine lymphocyte proliferation impaired by substituted neosolaniols and calonectrins-Fusarium metabolites associated with trichothecene biosynthesis. Toxicon 1991, 29, 1107-1113.

71. Alexander, N.J.; McCormick, S.P.; Ziegenhorn, S.L. Phytotoxicity of selected trichothecenes using Chlamydomonas reinhardtii as a model system. Nat. Toxins 1999, 7, 265-269.

72. Desjardins, A.E.; McCormick, S.P.; Appell, M. Structure-activity relationships of trichothecene toxins in an Arabidopsis thaliana leaf assay. J. Agric. Food Chem. 2007, 55, 6487-6492.

73. Starkey, D.E.; Ward, T.J.; Aoki, T.; Gale, L.R.; Kistler, H.C.; Geiser, D.M.; Suga, H.; Tóth, B.; Varga, J.; O'Donnell, K. Global molecular surveillance reveals novel Fusarium head blight species and trichothecene toxin diversity. Fungal Genet. Biol. 2007, 44, 1191-1204.

74. Yang, L.; van der Lee, T.; Yang, X.; Yu, D.; Waalwijk, C. Fusarium populations on Chinese barley show a dramatic gradient in mycotoxin profiles. Phytopathology 2008, 98, 719-727.

75. Zhang, H.; Zhang, Z.; van der Lee, T.; Chen, W.Q.; Xu, J.; Xu, J.S.; Yang, L.; Yu, D.; Waalwijk, C.; Feng, J. Population genetic analyses of Fusarium asiaticum populations from barley suggest a recent shift favoring 3ADON producers in southern China. Phytopathology 2010, 100, 328-336.

76. Druzhinina, I.S.; Kubicek, C.P.; Komoń-Zelazowska, M.; Mulaw, T.B.; Bissett, J. The Trichoderma harzianum demon: Complex speciation history resulting in coexistence of hypothetical biological species, recent agamospecies and numerous relict lineages. BMC Evol. Biol. 2010, 10, 94 .

(C) 2011 by the authors; licensee MDPI, Basel, Switzerland. This article is an open access article distributed under the terms and conditions of the Creative Commons Attribution license (http://creativecommons.org/licenses/by/3.0/). 